\title{
Efeitos de Regras com Diferentes Extensões sobre o Comportamento Humano
}

\author{
Luiz Carlos de Albuquerque ${ }^{1}$ \\ Universidade Federal do Pará \\ Karina Vasconcelos Darwich Ferreira \\ Secretaria Municipal de Saúde de Belém
}

\begin{abstract}
Resumo
Para investigar se a extensão de uma regra interfere no seguir regras, dezesseis estudantes universitários foram expostos a um procedimento de escolha segundo o modelo. Em cada tentativa, um estímulo modelo e três de comparação eram apresentados ao participante, que deveria apontar para os estímulos de comparação em seqüência. As seqüências corretas eram reforçadas. Cada condição era constituída de três sessões de trinta tentativas. As Sessões 1, 2 e 3 eram iniciadas por: Instruções mínimas na Condição I; Regras R1, R2 e R1, respectivamente, na Condição II; R2, R1 e R2, respectivamente, na Condição III, e R3, R1 e R3, respectivamente, na Condição IV. R3 era mais extensa que R2 e R2 mais extensa que R1. Os resultados mostraram que R1 e R2 foram sempre seguidas. R3 foi seguida apenas na terceira sessão da Condição IV. Sugere-se que a extensão e a complexidade de uma regra pode interferir no seguir regras.

Palavras-chave: Comportamento governado por regras; procedimento de escolha segundo o modelo; estudantes universitários.
\end{abstract}

Effect of Rules Size on Human Behavior

\begin{abstract}
In order to verify whether rule size affects rule following, 16 college students were exposed to a matching-to-sample procedure. Depending upon the sample three comparisons should be pointed in a different sequence. Correct sequencing was reinforced. Each condition had three sessions with 30 trials each, and started with one of three rules. Under Condition I, minimal instructions were given; under Condition II, rules R1, R2, and R1 were used, in this sequence; under Condition III, rules R2, R1, and R2 were used, in this sequence; and under Condition IV, rules R3, R1, and R3 were used, in this sequence. R3 was longer than R2, and R2 was longer than R1. Results showed that Rules 1 and 2 were always followed. Rule 3 was followed only in the third session, Condition IV. It is suggested that the size and complexity of a rule does affect rule following behavior. Keywords: Rule following behavior; matching-to-sample; college students.
\end{abstract}

$\mathrm{Na}$ literatura do comportamento governado por regras, grande parte dos autores (Baron \& Galizio, 1983; Galizio, 1979; Joyce \& Chase, 1990; Schlinger \& Blakely, 1987; Skinner, 1980, 1982), tem considerado regras como estímulos antecedentes que podem descrever contingências, isto é, que podem descrever o comportamento a ser emitido, as condições sob as quais ele deve ser emitido e suas prováveis conseqüências. Por esta definição, instruções, avisos, conselhos, ordens, leis, seriam exemplos particulares de regras, uma vez que todos podem descrever contingências (Skinner, 1982). Ainda de acordo com Skinner (1980, 1982), regras exercem controle como estímulo discriminativo fazendo parte de um conjunto de contingências de reforço. Por essa proposição, regras são seguidas porque o comportamento de seguir regras similares foi reforçado no passado.

\footnotetext{
${ }^{1}$ Endereço para correspondência: Rua Oliveira Belo, 238/1702, 66.050380, Umarizal, Belém, PA. Fone: (91) 223.8995. E-mail: lca@cpgp.ufpa.br
}

Os procedimentos usados para avaliar o controle por regras sobre o comportamento humano consistem, em geral, em apresentar ao ouvinte uma instrução que descreve o padrão de respostas apropriado a um determinado esquema de reforçamento e, em seguida, expor o ouvinte ao esquema descrito na instrução. Passado um certo tempo, pressionando uma chave e obtendo pontos trocáveis por dinheiro de acordo com a interação instrução/esquema, o esquema é mudado sem que o ouvinte seja avisado. Observa-se, então, após a mudança do esquema, se o ouvinte continua apresentando o padrão de respostas previamente descrito na instrução ou se muda o seu comportamento acompanhando as mudanças nas contingências de reforço. No primeiro caso, diz-se que o comportamento é controlado por regras, no segundo que é controlado por contingências (Albuquerque, 1998; Baron \& Galizio, 1983; Chase \& Danforth, 1991).

A maior parte dos estudos, na linha de pesquisa do comportamento governado por regras, tem investigado 
as condições sob as quais o seguimento de regras é mais ou menos provável de ser mantido (Albuquerque, 1998; Baron, Kaufman \& Stauber, 1969; Galizio, 1979; Hayes, Brownstein, Haas \& Greenway, 1986; Hayes, Brownstein, Zettle, Rosenfarb \& Korn, 1986; Joyce \& Chase, 1990; LeFrancois, Chase \& Joyce, 1988; Paracampo, Albuquerque \& Fontes, 1993; Shimoff, Catania \& Matthews, 1981; Shimoff, Matthews \& Catania, 1986; Weiner, 1970).

Alguns destes estudos têm sugerido que o comportamento de seguir regras pode ser mantido quando as regras correspondem às contingências de reforço e o comportamento de seguir regras produz conseqüências reforçadoras (Albuquerque, 1998; Baron \& Galizio, 1983; Galizio, 1979; Joyce \& Chase, 1990). Além disso, quando a correspondência entre a regra e o comportamento de segui-la é monitorada por membros da comunidade verbal identificados como "autoridades", o comportamento de seguir regras pode ser mantido mesmo quando produz conseqüências que contradizem a própria regra (Albuquerque, 1998).

Por outro lado, o comportamento de seguir regras pode deixar de ocorrer quando mantém contato prolongado com conseqüências que contradizem a própria regra (Baron \& Galizio, 1983; Bernstein, 1988; Michael \& Bernstein, 1991; Galizio, 1979; Hayes, Brownstein, Zettle, Rosenford \& Korn, 1986; Paracampo e colaboradores, 1993; Perone, Galizio \& Baron, 1988; Shimoff e colaboradores, 1981) e quando é antecedido por condições que geram variação comportamental (Chase \& Danforth, 1991; Joyce \& Chase, 1990; LeFrancois e colaboradores, 1988).

Investigando as condições sob as quais o seguimento de regras é mais ou menos provável de ser mantido, alguns destes estudos manipularam as conseqüências programadas para o comportamento de seguir regras (Galizio, 1979; Hayes, Brownstein, Zettle e colaboradores, 1986; Shimoff e colaboradores, 1981), outros manipularam as condições antecedentes ao comportamento de seguir regras (Albuquerque, 1998; Torgrud \& Holborn, 1990) e outros manipularam tanto as condições antecedentes quanto as conseqüências programadas para o comportamento de seguir regras (Joyce \& Chase, 1990; LeFrancois e colaboradores, 1988). Contudo nenhum destes estudos chegou a manipular a própria regra com o objetivo de investigar se a extensão de uma regra, medida pelo número de diferentes respostas descritas na própria regra, interfere no seguimento de regra. A investigação dessa possibilidade, no entanto, é importante porque também pode contribuir para delimitar as condições sob as quais o seguimento de regras é mais ou menos provável de ocorrer. Isto considerando que, de acordo com Skinner (1978), à medida que uma instrução se torna cada vez mais complexa, atingir-se-á um ponto no qual o ouvinte será incapaz de segui-la de forma apropriada.

"O ouvinte que responde corretamente a Coloque a mão direita no ouvido esquerdo, por exemplo, pode revelar sinais de confusão ao responder a Encoste a mão esquerda no ouvido direito, a mão direita no nariz, pisque o olbo esquerdo e ponha o pé direito à frente" (Skinner, 1978, p.438).

Assim, se a extensão de uma regra interfere no seguimento de regra, poder-se-ia supor que, quanto maior a extensão de uma regra (isto é, quanto maior o número de diferentes respostas descritas na regra) menor a possibilidade dessa regra ser seguida. Por outro lado, quanto menor a extensão de uma regra (isto é, quanto menor o número de diferentes respostas descritas na regra) maior a possibilidade dessa regra ser seguida. Estas diferenças deveriam ocorrer mesmo quando, nos dois casos, o seguimento de regra produzisse conseqüências reforçadoras. Isto é, mesmo quando a regra correspondesse às contingências de reforço programadas no experimento.

Considerando isto, o presente estudo procurou investigar se a extensão de uma regra interfere no seguimento de regra, quando o comportamento de seguir regra é reforçado em esquema de reforçamento contínuo (CRF) e a extensão da regra é medida pelo número de diferentes respostas descritas na própria regra.

Uma maneira de avaliar esse objetivo seria apresentar ao ouvinte regras correspondentes com diferentes extensões e observar se as regras são seguidas. Um problema que surge, no entanto, quando se pretende avaliar os efeitos de regras correspondentes é o de separar o controle por regras do controle pelas contingências de reforço programadas no experimento. Alguns autores (Catania, Shimoff \& Matthews, 1989) argumentam que, quando regras correspondem às contingências de reforço (isto é, quando o comportamento especificado pela regra é semelhante ao comportamento que produz reforço) não há base para decidir se é a regra ou as contingências que exercem controle. Neste caso, tem sido sugerido que se o comportamento for estabelecido por uma regra, pode-se dizer que este comportamento está sob controle de regra, mesmo que ele apresente o padrão característico do esquema a que foi submetido (Catania e colaboradores, 1989; Hayes, Brownstein, Haas \& Greenway, 1986; Shimoff e colaboradores, 1986). Entretanto, tem sido proposto que o verdadeiro seguimento de regra ocorre apenas antes que o comportamento de seguir regra tenha tido oportunidade 
de ser afetado pelas conseqüências (Andronis, 1991; Joyce \& Chase, 1990; Paracampo, 1991). Depois disso, o comportamento é controlado por contingências (Andronis, 1991; Joyce \& Chase, 1990).

Considerando isto, o presente estudo pretende investigar o objetivo proposto através de um procedimento de escolha de acordo com o modelo, similar ao que tem sido usado por Albuquerque (Albuquerque, 1989, 1991, 1998), analisando-se os efeitos do procedimento em cada indivíduo independentemente. Este procedimento foi usado porque permite avaliar, a cada tentativa, se as respostas emitidas pelo ouvinte se alternam ordenadamente entre as dimensões dos estímulos de comparação, de acordo com a ordem previamente descrita na regra, ou com as contingências de reforço, ou com a interação entre a regra e essas contingências.

Assim, no presente estudo, será dito que o comportamento que se seguir a apresentação de uma regra foi estabelecido por regra, quando a combinação de três condições for satisfeita: 1) quando o comportamento observado for o especificado na regra, emitido na presença dos estímulos descritos pela regra, e na seqüência descrita na regra; 2) quando este comportamento ocorrer antes mesmo que as conseqüências programadas no experimento possam exercer algum efeito sobre ele; e, 3) quando este comportamento mudar de acordo com as mudanças das regras.

Será dito que o comportamento observado foi estabelecido pelas conseqüências de reforço programadas no experimento quando a combinação de duas condições for satisfeita: 1) quando o comportamento observado for o reforçado; e, 2) quando este comportamento ocorrer na ausência de uma descrição antecedente verbal, especificando que comportamento na presença de que estímulo poderá ser reforçado.

E será dito que o comportamento que se seguir a apresentação de uma regra está sob controle da interação entre a regra e as contingências de reforço, quando a combinação de duas condições for satisfeita: 1) quando o comportamento observado for o especificado na regra, emitido na presença dos estímulos descritos pela regra, e na seqüência descrita na regra; e, 2) quando este comportamento estiver sendo reforçado.

\section{Participantes}

\section{Método}

Participaram 16 estudantes universitários, de diversos cursos (exceto Psicologia), dez mulheres e seis homens, com idades variando entre vinte e vinte e nove anos, matriculados em diferentes semestres. Todos foram convidados a participar do experimento, como se segue: "Estou realizando uma pesquisa sobre aprendizagem e queria saber se você estaria interessado em participar. $\mathrm{O}$ objetivo da pesquisa é investigar processos de aprendizagem comuns a todas as pessoas. A pesquisa será realizada em um único dia da semana e terá a duração de, aproximadamente, uma hora e meia. A pessoa que participar receberá passagem de ônibus de ida e volta à universidade. Você está interessado em participar?"

\section{Material}

Foi utilizada uma mesa de madeira. Fixado à mesa, de modo a dividi-la ao meio, havia um anteparo com espelho unidirecional, fixado em uma moldura de madeira e localizado acima do tampo da mesa. No centro do anteparo, junto ao tampo da mesa, havia uma abertura retangular. Acima e ao centro desta abertura, havia um contador operado pelo experimentador e com os dígitos voltados para o participante. Visíveis ao participante estavam instaladas no anteparo três lâmpadas transparentes de cinco watts, dispostas em fileira e distantes $4 \mathrm{~cm}$ uma da outra. Três etiquetas de papel estavam colocadas no anteparo, acima de cada lâmpada. A etiqueta à esquerda tinha impressa a letra ' $E$ ', a do centro, a letra 'C', e a da direita, a letra 'D'. Uma lâmpada fluorescente de 15 watts estava instalada na borda superior e ao centro do anteparo. Ao lado direito do experimentador, havia uma fita cassete, um amplificador e um tape-deck. Conectados ao tape-deck, havia dois fones de ouvido. A mesa estava situada no centro de uma sala.

Os estímulos modelo e de comparação foram 192 peças de madeira, partes de quatro conjuntos iguais de blocos lógicos (marca FUNBEC), variando em três dimensões: forma (quadrado, círculo, retângulo e triângulo), cor (azul, vermelha e amarela) e espessura (grossa e fina). Estas peças de madeira formavam 30 diferentes arranjos de estímulos, cada um constituído de um estímulo modelo e três estímulos de comparação. Cada estímulo de comparação apresentava apenas uma dimensão (cor, espessura ou forma) em comum com o estímulo modelo e diferia nas demais. A combinação dos estímulos era aleatória, assim como a ordem de apresentação dos 30 arranjos. Os arranjos de estímulos previamente preparados ficavam sobre a mesa, ao lado do experimentador, na ordem em que seriam apresentados em cada tentativa sucessiva. Para facilitar o manejo dos arranjos, sentado ao lado esquerdo do experimentador, um auxiliar de pesquisa aproximava os arranjos, conforme os mesmos iam sendo apresentados. Os estímulos eram apresentados ao participante através da abertura retangular na base do anteparo divisor da 
mesa, em uma bandeja de madeira em forma de ' $\mathrm{T}$ '. $\mathrm{Na}$ parte final do cabo dessa bandeja, rente à base retangular, quatro ripas de madeira formavam um quadrado, no qual era colocado o estímulo modelo. $\mathrm{Na}$ base retangular da bandeja, dividida por ripas de madeira em três quadrados, eram apresentados os três estímulos de comparação.

As respostas de escolha emitidas pelos participantes eram registradas pelo experimentador em um protocolo previamente preparado e eram também gravadas por uma filmadora, para análises posteriores.

\section{Situação Experimental}

Durante as sessões experimentais, participante e experimentador ficavam sentados à mesa de frente um para o outro, separados pelo anteparo divisor da mesa. A lâmpada na borda superior do anteparo ficava constantemente acesa, voltada para o participante, de maneira a assegurar que seu lado apresentasse iluminação em maior intensidade, garantindo que apenas as ações emitidas pelo participante, bem como o arranjo dos estímulos apresentados, pudessem ser observados através do espelho. As três lâmpadas transparentes eram acesas apenas nas sessões iniciadas pelas instruções que descreviam essas lâmpadas. Nessas sessões o experimentador inicialmente apresentava ao participante uma determinada instrução, em seguida acendia uma dessas três lâmpadas, e logo após, apresentava os arranjos de estímulos. Nas sessões iniciadas pelas instruções que não descreviam lâmpadas, o experimentador apresentava uma determinada instrução e em seguida os arranjos de estímulos. As sessões, realizadas em um único dia, duravam em média 30 minutos e o intervalo entre sessões era de aproximadamente 5 minutos.

Em cada tentativa, após o experimentador apresentar um dos 30 arranjos de estímulos, e enquanto este ainda estava presente, o participante deveria apontar para os estímulos de comparação em uma dada seqüência. Caso a seqüência de respostas emitida estivesse de acordo com as contingências de reforço programadas, um ponto era acrescentado no contador (se a sessão tivesse sido iniciada por uma instrução que descrevia as lâmpadas transparentes, a lâmpada que havia sido acesa era apagada) e a bandeja com o arranjo de estímulos era retirada. Caso a seqüência de respostas fosse incorreta (se a sessão tivesse sido iniciada por uma instrução que descrevia as lâmpadas transparentes, a lâmpada que havia sido acesa era apagada) e a bandeja era retirada, sem ser acrescentado um ponto no contador. Havia um intervalo variável de aproximadamente 5 segundos entre uma tentativa e outra.

\section{Procedimentos}

\section{Orientações Preliminares}

$\mathrm{Na}$ primeira sessão, quando o participante e o experimentador entravam na sala experimental, a bandeja com os arranjos de estímulos estava sobre a mesa, visível ao participante. O experimentador pedia ao participante para sentar-se na cadeira e, ao lado do participante, sempre apontando com o dedo para cada um dos estímulos a que se referia, dizia: "Este objeto aqui em cima, é um modelo. Estes três objetos aqui em baixo, são para você comparar com o modelo. Nós vamos chamá-los de objetos de comparação. Observe que cada um destes três objetos de comparação tem uma única propriedade comum ao modelo. Veja. Este só tem a cor em comum com o modelo. Este aqui só tem a espessura comum ao modelo. Este aqui só tem a forma igual ao modelo. Durante a pesquisa você poderá ganhar pontos que serão trocados por dinheiro. Cada ponto que você ganhar será trocado por CR $\$ 3,00$ (três cruzeiros reais) ${ }^{2}$, mas apenas no final da pesquisa. Quando você ganhar pontos, os pontos sempre aparecerão aqui neste contador. Veja como os pontos aparecem no contador (o auxiliar, que já se encontrava no outro lado da mesa, acionava o contador por cinco vezes). Entendeu?"

\section{Regras}

A seguir, o experimentador pedia para o participante colocar os fones de ouvido e deslocava-se em direção a sua cadeira. Separado do participante pelo anteparo com o espelho unidirecional, o experimentador também colocava os seus fones de ouvido e, dependendo da condição experimental, entregava ao participante, pela abertura na base do anteparo, uma folha de papel contendo uma das seguintes instruções (regras) datilografadas (ver Anexo A):

Instruções mínimas: Estas instruções não especificavam qualquer seqüência de respostas.

Regra R1: Esta regra especificava que o participante deveria emitir a seqüência de respostas espessura (E) forma $(\mathrm{F})-\operatorname{cor}(\mathrm{C})$.

Regra R2: Esta regra especificava que o participante deveria emitir as seqüências de respostas CFE, FEC e ECF quando as luzes da esquerda, do centro e da direita fossem acesas, respectivamente.

Regra R3: Esta regra especificava que o participante deveria emitir as seqüencias de respostas CEFEFC, FECECF e ECFFCE quando as luzes da esquerda, do centro e da direita fossem acesas, respectivamente.

\footnotetext{
2 Moeda em vigor no país em 1993, ano em que os dados do presente estudo foram coletados.
} 
As Regras R1, R2 e R3 eram correspondentes às contingências de reforço em vigor nas sessões em que eram apresentadas.

\section{Delineamento Experimental}

Os participantes foram divididos em quatro condições experimentais, conforme a Tabela 1. Cada condição era constituída de três sessões e era realizada com quatro participantes. Cada sessão, constituída de trinta tentativas, durava em média 30 minutos e os intervalos entre as sessões eram de 5 minutos, aproximadamente. Uma sessão tinha o seu início com a apresentação de uma instrução ao participante e o seu encerramento, após a trigésima tentativa, com a saída do participante da sala experimental.

$\mathrm{Na}$ Condição I (IM), eram apresentadas apenas as instruções mínimas no início de cada uma das três sessões. $\mathrm{Na}$ Condição II (R1-R2-R1), os participantes eram expostos à Regra R1 no início da primeira sessão, à Regra R2 início da segunda sessão e novamente à Regra R1 início da terceira sessão. Na Condição III (R2-R1-R2), eram expostos às Regras R2, R1 e R2 no início das Sessões 1, 2 e 3, respectivamente. Na Condição IV (R3-R1-R3), eram expostos às Regras R3, R1 e R3 no início das Sessões 1,2 e 3, respectivamente.

Nas sessões em que as instruções mínimas e a Regra R1 eram apresentadas, as três lâmpadas transparentes não eram acesas. Estas lâmpadas eram acesas apenas nas sessões em que a Regra R2 e a Regra R3 eram apresentadas. Nas sessões em que as Regras R 2 e R 3 eram apresentadas, a lâmpada da esquerda era acesa nas dez primeiras tentativas; a lâmpada do centro, nas dez tentativas subseqüentes e, a lâmpada da direita, nas dez últimas tentativas. Assim, as lâmpadas eram acesas na seguinte ordem, previamente determinada: esquerda centro - direita. Em cada tentativa dessas sessões, sempre primeiro uma lâmpada era acesa e em seguida um arranjo, constituído de um estímulo modelo e três de comparação, era apresentado. Quando uma lâmpada estava acesa, as outras duas ficavam apagadas. Depois de acesa, uma

Tabela 1. Esquema do Procedimento.

\begin{tabular}{|c|c|c|c|}
\hline Condições & Sessão 1 & Sessão 2 & Sessão 3 \\
\hline I & Instruções mínimas & Instruções mínimas & Instruções mínimas \\
\hline (Instruções & Seqüência Reforçada: & Seqüência Reforçada: & Seqüência Reforçada: \\
\hline mínimas) & $\mathrm{EFC}$ & $\mathrm{EFC}$ & $\mathrm{EFC}$ \\
\hline \multirow{5}{*}{$\begin{array}{c}\text { II } \\
\text { (R1-R2-R1) }\end{array}$} & Regra R1 & Regra R2 & Regra R1 \\
\hline & Seqüência Reforçada: & Seqüências Reforçadas: & Seqüência Reforçada: \\
\hline & EFC & CFE - lâmpada da & EFC \\
\hline & & esquerda. & \\
\hline & & $\begin{array}{l}\text { FEC - lâmpada do centro. } \\
\text { ECF - lâmpada da direita. }\end{array}$ & \\
\hline \multirow{5}{*}{$\begin{array}{c}\text { III } \\
\text { (R2-R1-R2) }\end{array}$} & Regra R2 & Regra R1 & Regra R2 \\
\hline & Seqüências Reforçadas: & Seqüência Reforçada: & Seqüências Reforçadas: \\
\hline & CFE - lâmpada da esquerda. & $\mathrm{EFC}$ & CFE - lâmpada da esquerda. \\
\hline & FEC - lâmpada do centro. & & FEC - lâmpada do centro. \\
\hline & ECF - lâmpada da direita & & ECF - lâmpada da direita \\
\hline \multirow{5}{*}{$\begin{array}{c}\text { IV } \\
\text { (R3-R1-R3) }\end{array}$} & Regra R3 & Regra R1 & Regra R3 \\
\hline & Seqüências Reforçadas: & Seqüência Reforçada: & Seqüências Reforçadas: \\
\hline & CEFEFC - lâmpada da esquerda. & EFC & CEFEFC - lâmpada da \\
\hline & FECECF - lâmpada do centro. & & esquerda. \\
\hline & ECFFCE - lâmpada da direita. & & $\begin{array}{l}\text { FECECF - lâmpada do centro. } \\
\text { ECFFCE - lâmpada da direita. }\end{array}$ \\
\hline
\end{tabular}

Nota: Cada condição foi realizada com quatro participantes. $\mathrm{C}=$ Resposta à dimensão cor; $\mathrm{E}=$ Resposta à espessura; $\mathrm{F}=$ Resposta à forma. As Instruções mínimas não especificavam seqüências de respostas; A Regra R1 especificava a seqüência EFC; A Regra R2 especificava CFE, FEC e ECF e a Regra R3 especificava CEFEFC, FECECF e ECFFCE, na presença das lâmpadas da esquerda, do centro e da direita, respectivamente 
lâmpada só era apagada após o participante completar a seqüência de respostas que deveria ser emitida na sua presença, de acordo com a regra.

Nas quatro condições, quando uma seqüência era reforçada, era reforçada em esquema de reforçamento contínuo (CRF). Em cada condição, as seqüências reforçadas eram consideradas corretas e as seqüências não reforçadas, consideradas incorretas. As seqüências eram reforçadas com pontos que eram trocados por dinheiro.

$\mathrm{Na}$ Condição I, apenas a emissão da seqüência EFC (seqüência não instruída) era reforçada diferencialmente em CRF. A emissão de qualquer outra seqüência não era reforçada. Na Condição II, nas Sessões 1 e 3, era reforçada apenas a emissão da seqüência EFC, especificada pela Regra R1. Na Sessão 2 eram reforçadas apenas as seqüências especificadas pela Regra R2, tal como se segue: Da primeira a décima tentativa, quando a lâmpada da esquerda era acesa, era reforçada apenas a seqüência CFE. Da décima primeira a vigésima tentativa, quando a lâmpada do centro era acesa, era reforçada apenas a seqüência FEC. E da vigésima primeira a trigésima tentativa, quando a lâmpada da direita era acesa, era reforçada apenas a seqüência ECF. A emissão de qualquer outra seqüência não era reforçada na Condição II.

$\mathrm{Na}$ Condição III, nas Sessões 1 e 3, eram reforçadas apenas as seqüências especificadas pela Regra R2. A seqüência CFE era reforçada apenas nas dez primeiras tentativas, quando a lâmpada da esquerda era acesa. A seqüência FEC era reforçada apenas nas dez tentativas subseqüentes, quando a lâmpada do centro era acesa. E a seqüência ECF era reforçada apenas nas dez últimas tentativas, quando a lâmpada da direita era acesa. $\mathrm{Na}$ Sessão 2, era reforçada apenas a seqüência EFC, especificada pela Regra R1. Emissão de qualquer outra seqüência não era reforçada na Condição III.

$\mathrm{Na}$ Condição IV, nas Sessões 1 e 3, eram reforçadas apenas as seqüências especificadas pela Regra R3. A seqüência CEFEFC era reforçada apenas nas dez primeiras tentativas, quando a lâmpada da esquerda era acesa. A seqüência FECECF era reforçada apenas nas dez tentativas subseqüentes, quando a lâmpada do centro era acesa. E a seqüência ECFFCE era reforçada apenas nas dez últimas tentativas, quando a lâmpada da direita era acesa. $\mathrm{Na}$ Sessão 2, era reforçada apenas a seqüência EFC, especificada pela Regra R1. Emissão de qualquer outra seqüência não foi reforçada na Condição IV.

Em síntese, nas sessões em que as instruções mínimas e a Regra R1 eram apresentadas, um ponto era acrescentado no contador toda vez que o participante emitisse a seqüência EFC. Emissão de qualquer outra seqüência não era seguida de reforço. Nas sessões em que a Regra R2 era apresentada, um ponto era acrescentado no contador toda vez que o participante emitisse as seqüências CFE nas dez primeiras tentativas (quando a lâmpada da esquerda era acesa), FEC nas dez tentativas subseqüentes (quando a lâmpada do centro era acesa) e ECF nas dez últimas tentativas (quando a lâmpada da direita era acesa). E nas sessões em que a Regra R3 era apresentada, um ponto era acrescentado no contador, toda vez que o participante emitisse as seqüências CEFEFC nas dez primeiras tentativas (quando a lâmpada da esquerda era acesa), FECECF nas dez tentativas subseqüentes (quando a lâmpada do centro era acesa) e ECFFCE nas dez últimas tentativas (quando a lâmpada da direita era acesa).

\section{Forma de Apresentação das Regras}

Foi apresentada uma instrução no início de cada sessão. No início de cada sessão, imediatamente após o participante receber a folha de papel contendo as instruções datilografadas, o experimentador ligava o gravador e, através dos fones de ouvido, o participante passava a ouvir uma fita, previamente gravada, que dizia: "Eu vou ler estas instruções para você em voz alta, acompanhe a minha leitura, lendo em voz baixa". A gravação continuava com a leitura das instruções contidas na folha de papel. Terminada esta leitura, a gravação prosseguia: "Agora, você deve ler estas instruções sozinho, em voz baixa. Leia com calma e com bastante atenção. Você tem todo o tempo que achar necessário para entendê-las". A gravação era interrompida e logo após o participante avisar que havia terminado esta segunda leitura, a gravação prosseguia: "Eu vou ler mais uma vez estas instruções para você, acompanhe a minha leitura, lendo em voz baixa". A gravação continuava com a leitura das instruções escritas. Terminada essa terceira leitura, a gravação prosseguia: "Devolva-me a folha com as instruções. Eu só posso falar com você no final da pesquisa. Você pode retirar os fones de ouvido agora".

Durante a leitura do trecho das instruções que dizia: "Quando a lâmpada da esquerda estiver acesa (essa que tem a letra ' $E$ ' em cima)", o experimentador acendia e apagava a lâmpada da esquerda. Do mesmo modo, o experimentador também acendia e apagava as lâmpadas do centro e da direita, quando as instruções se referiam a essas lâmpadas.

Logo após o participante devolver a folha com as instruções, o experimentador removia a bandeja, voltava a apresentar a bandeja com um outro arranjo de estímulos e dizia: "Comece a apontar". Nas sessões iniciadas pela Regra R2 ou pela Regra R3, o experimentador acendia a 
lâmpada da esquerda, antes de voltar a apresentar a bandeja com um novo arranjo de estímulos e de pedir para o participante começar a apontar.

\section{Comparação dos registros}

Após a última sessão, um observador independente comparava o registro feito pelo experimentador com o registro feito pela filmadora. Caso houvesse $100 \%$ de concordância entre os registros, os dados do participante eram considerados para análise. Caso contrário, os dados do participante eram descartados por erro do experimentador na condução da sessão. No presente estudo, não foram descartados dados por essa razão.

\section{Término de Sessão e da Participação do participante no Experimento}

O participante podia ganhar no máximo 30 pontos por sessão. Cada ponto valia CR \$3,00 (três cruzeiros reais), mas o total de pontos obtidos em cada sessão somente era trocado por dinheiro ao final da pesquisa. Os pontos foram registrados cumulativamente entre as sessões. Assim, o total de pontos obtidos dentro de uma sessão ficava registrado no contador (visível ao participante) nas sessões seguintes. A participação do participante no experimento era encerrada depois de completada a terceira sessão.
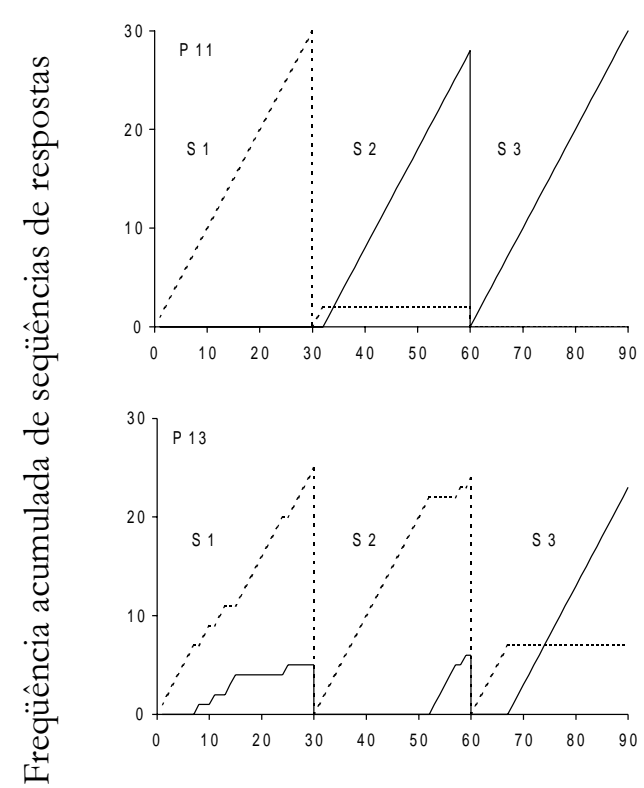

\section{Resultados}

A Figura 1 mostra as seqüências de respostas corretas e incorretas apresentadas pelos participantes da Condição I (Instruções mínimas). Pode-se observar que nenhum dos quatro participantes (P11, P12, P13 e P14) apresentou um responder discriminado, de acordo com as contingências de reforço nesta sessão. Os participantes só passaram a responder consistentemente na seqüência EFC, de acordo com as contingências de reforço, a partir da segunda (caso de P11) ou da terceira sessão (caso de P12, P13 e P14).

A Tabela 2 mostra as porcentagens de seqüências de respostas corretas apresentadas pelos participantes durante as Sessões 1, 2 e 3 das Condições II, III e IV.

A Figura 2 mostra as seqüências de respostas corretas e incorretas apresentadas pelos participantes da Condição II (R1-R2-R1). Pode-se observar nesta figura que todos os quatro participantes (P21, P22, P23 e P24), antes de ganhar o primeiro ponto, iniciaram a primeira sessão emitindo a seqüência especificada pela Regra R1 (seqüência EFC) e continuaram apresentando esta seqüência correta em mais de $83 \%$ das tentativas dessa sessão (ver Tabela 2). Na segunda sessão, quando a Regra R2 foi apresentada, três participantes (P21, P23 e P24) passaram a responder tal como descrito na Regra R2, emitindo as seqüências
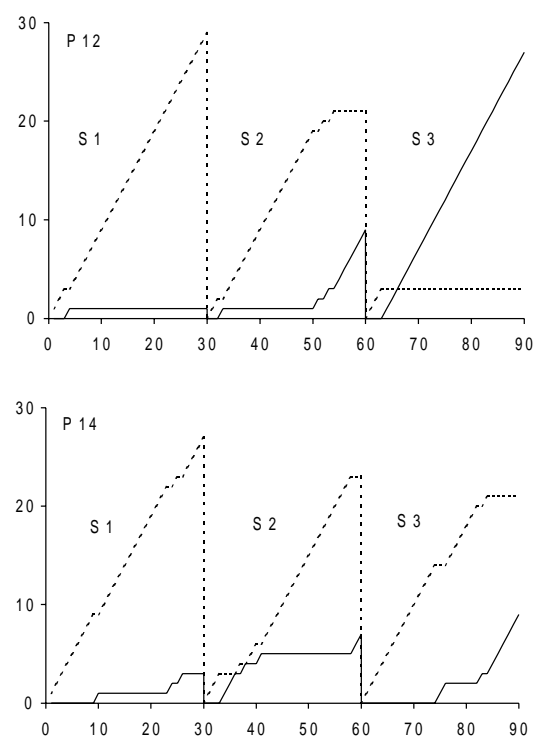

Tentativas

Figura 1. Freqüência acumulada de seqüências de respostas corretas (linha sólida) e incorretas (linha tracejada), para cada participante $(\mathrm{P})$ da Condição I, durante cada sessão (S) experimental. Quebras na curva acumulada indicam mudanças de sessão. 
Tabela 2. Porcentagens de Seqüências de Respostas Corretas Apresentadas pelos Participantes durante as Sessões 1, 2 e 3 das Condições II, III e IV

\begin{tabular}{|c|c|c|c|c|c|c|c|c|c|c|}
\hline \multirow{3}{*}{$\begin{array}{c}\text { Condições } \\
\text { II }\end{array}$} & \multirow[t]{2}{*}{ Participantes } & \multicolumn{3}{|c|}{ Sessão 1} & \multicolumn{3}{|c|}{ Sessão 2} & \multicolumn{3}{|c|}{ Sessão 3} \\
\hline & & \multicolumn{3}{|c|}{ Tentativas } & \multicolumn{3}{|c|}{ Tentativas } & \multicolumn{3}{|c|}{ Tentativas } \\
\hline & P21 & \multicolumn{3}{|c|}{$1-30$} & $1-10$ & $11-20$ & $21-30$ & \multicolumn{3}{|c|}{$1-30$} \\
\hline \multirow[t]{6}{*}{ (R1-R2-R2) } & P22 & \multicolumn{3}{|c|}{100} & 90 & 90 & 100 & \multicolumn{3}{|c|}{97} \\
\hline & P23 & \multicolumn{3}{|c|}{97} & 90 & 80 & 90 & \multicolumn{3}{|c|}{97} \\
\hline & P24 & \multicolumn{3}{|c|}{83} & 100 & 80 & 100 & \multicolumn{3}{|c|}{100} \\
\hline & & \multicolumn{3}{|c|}{100} & 100 & 100 & 100 & \multicolumn{3}{|c|}{100} \\
\hline & & \multicolumn{3}{|c|}{ Tentativas } & \multirow{2}{*}{\multicolumn{3}{|c|}{$\begin{array}{c}\text { Tentativas } \\
1-30\end{array}$}} & \multicolumn{3}{|c|}{ Tentativas } \\
\hline & & $1-10$ & $11-20$ & $21-30$ & & & & $1-10$ & $11-20$ & $21-30$ \\
\hline \multirow{4}{*}{$\begin{array}{c}\text { III } \\
(\mathrm{R} 2-\mathrm{R} 1-\mathrm{R} 2)\end{array}$} & P31 & 90 & 80 & 90 & & 97 & & 90 & 90 & 100 \\
\hline & P32 & 60 & 100 & 100 & & 90 & & 80 & 80 & 100 \\
\hline & P33 & 100 & 80 & 100 & & 100 & & 100 & 90 & 90 \\
\hline & P34 & 100 & 100 & 100 & & 100 & & 100 & 90 & 90 \\
\hline \multirow{6}{*}{$\begin{array}{c}\text { IV } \\
\text { (R3-R1-R3) }\end{array}$} & & \multicolumn{3}{|c|}{ Tentativas } & \multicolumn{3}{|c|}{ Tentativas } & \multicolumn{3}{|c|}{ Tentativas } \\
\hline & & $1-10$ & $11-20$ & $21-30$ & & $1-30$ & & $1-10$ & $11-20$ & $21-30$ \\
\hline & P41 & 70 & 0 & 0 & & 100 & & 100 & 90 & 100 \\
\hline & P42 & 10 & 0 & 20 & & 100 & & 80 & 90 & 100 \\
\hline & P43 & 100 & 30 & 70 & & 100 & & 100 & 90 & 100 \\
\hline & P44 & 0 & 0 & 0 & & 100 & & 90 & 80 & 80 \\
\hline
\end{tabular}
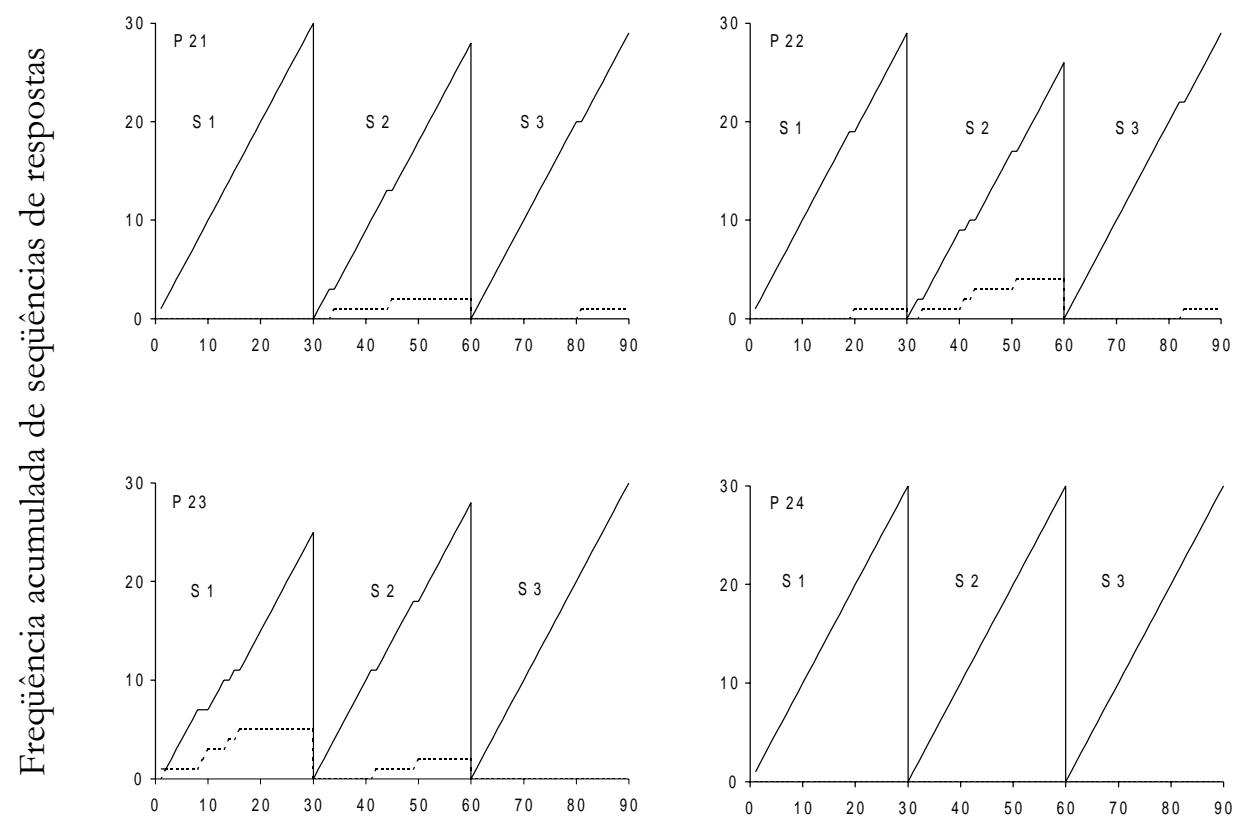

\section{Tentativas}

Figura 2. Freqüência acumulada de seqüências de respostas corretas (linha sólida) e incorretas (linha tracejada), para cada participante $(\mathrm{P})$ da Condição II, durante cada sessão (S) experimental. Quebras na curva acumulada indicam mudanças de sessão. 
corretas nas tentativas 1,11 e 21 . Na Tabela 2 pode-se notar que estes participantes (P21, P23 e P24) emitiram as seqüências corretas em mais de $80 \%$ das vezes em que os arranjos de estímulos foram apresentados nas tentativas de 1-10, 11-20 e 21-30. O Participante P22, contudo, embora tenha apresentado a seqüência correta em $80 \%$ das vezes nas tentativas de $11-20$ e em $90 \%$ das vezes nas tentativas de 21-30, não emitiu as seqüências corretas nas tentativas 11 e 21 dessa sessão. Na terceira sessão, quando a Regra R1 voltou a ser apresentada, todos os quatro participantes voltaram a apresentar a seqüência especificada pela Regra R1 em mais de $97 \%$ das tentativas dessa sessão.

A Figura 3 mostra as seqüências de respostas corretas e incorretas apresentadas pelos participantes da Condição III (R2-R1-R2). Pode-se observar que na primeira sessão todos os participantes (P31, P32, P33 e P34) responderam na presença dos estímulos de comparação, tal como descrito previamente na Regra R2, emitindo as seqüências corretas nas tentativas 1,11 e 21 . Na Tabela 2 pode-se notar que estes participantes emitiram as seqüências corretas em mais de $60 \%$ das vezes nas tentativas de 1 10, 11-20 e 21-30. Na segunda sessão, quando a Regra R1 foi apresentada, todos os quatro participantes passaram a responder tal como descrito na Regra R1, emitindo a seqüência correta em mais de $90 \%$ das tentativas dessa sessão. $\mathrm{Na}$ terceira sessão, quando a Regra R2 voltou a ser apresentada, os participantes voltaram a responder de acordo com a Regra 2, emitindo as seqüências corretas em mais de $80 \%$ das vezes nas tentativas de 1-10, 11-20 e 21-30. Embora o Participante P32 tenha emitido a seqüência correta em $80 \%$ das vezes nas tentativas de 11-20, este participante (P32) não emitiu a seqüência correta na tentativa 11 dessa sessão.

A Figura 4 mostra as seqüências de respostas corretas e incorretas apresentadas pelos participantes da Condição IV (R3-R1-R3). Pode-se observar que na primeira sessão, quando a Regra R3 foi apresentada, nenhum dos quatro participantes (P41, P42, P43 e P44) chegou a responder de acordo com esta regra nas tentativas 11 e 21, embora dois participantes (P42 e P43) tenham chegado a responder corretamente na tentativa 1 . Na Tabela 2 podese notar que três participantes (P41, P42 e P44) emitiram seqüências incorretas ao longo dessa sessão e um (P43) chegou a responder de acordo com a regra em 100\% das vezes nas tentativas de 1-10. Mas nas tentativas de 11-20, este participante (P43) emitiu a seqüência correta em apenas $30 \%$ dessas tentativas, e nas tentativas de 21 -
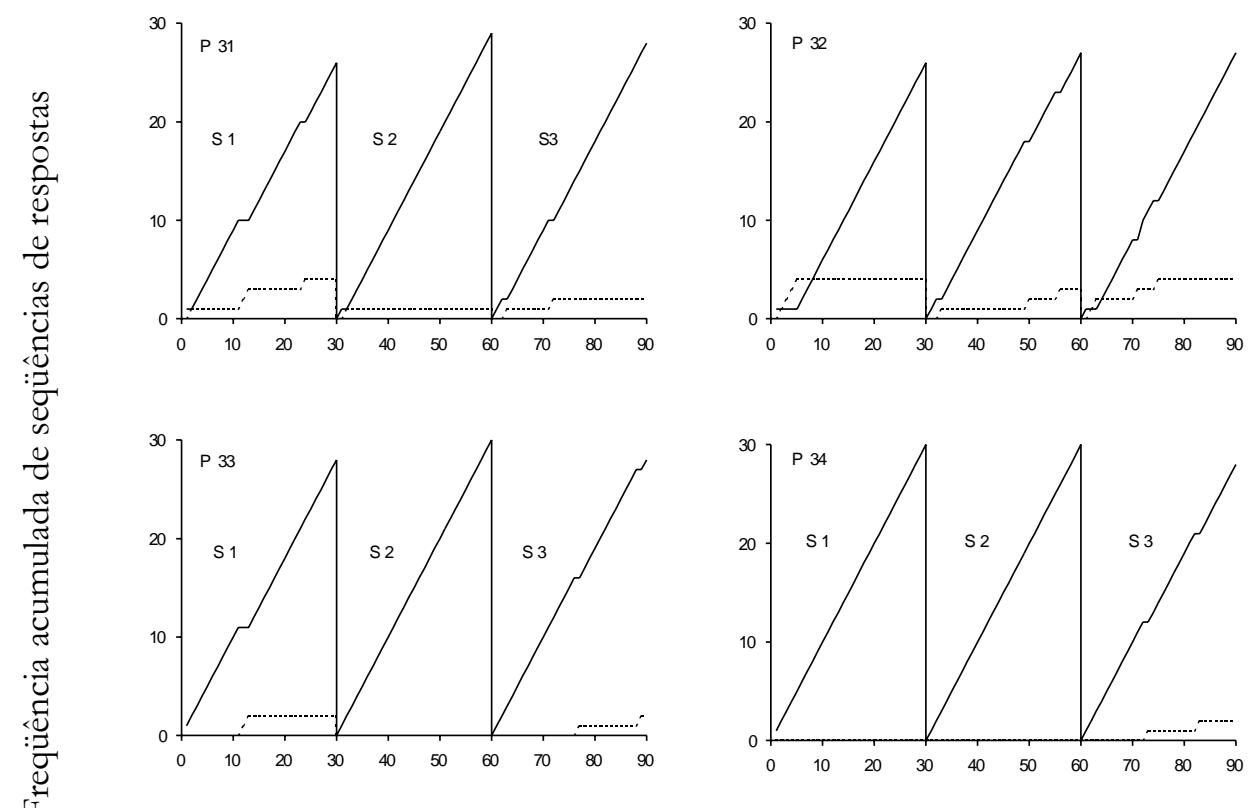

Tentativas

Figura 3. Freqüência acumulada de seqüências de respostas corretas (linha sólida) e incorretas (linha tracejada), para cada participante (P) da Condição III, durante cada sessão (S) experimental. Quebras na curva acumulada indicam mudanças de sessão. 
30, só passou a emitir a seqüência correta a partir da tentativa 24 (ver a Figura 4). Na segunda sessão, quando a Regra R1 foi apresentada, todos os quatro participantes passaram a responder tal como descrito na Regra R1, emitindo a seqüência correta em $100 \%$ das tentativas dessa sessão. Na terceira sessão, quando a Regra R3 voltou a ser apresentada, três participantes (P41, P43 e P 44) passaram a responder de acordo com a Regra 3, emitindo as seqüências corretas nas tentativas 1,11 e 21 . Na Tabela 2 pode-se notar que estes participantes (P41, P43 e P 44) emitiram as seqüências corretas em mais de $80 \%$ das vezes nas tentativas de 1-10, 11-20 e 21-30. O Participante P42 emitiu as seqüências corretas nas tentativas 1 e 21. Contudo, embora tenha emitido a seqüência correta em $90 \%$ das vezes nas tentativas de 11-20, este participante (P42) não emitiu a seqüência correta na tentativa 11 dessa sessão.

\section{Discussão}

$\mathrm{Na}$ literatura do comportamento governado por regras tem sido sugerido que a magnitude das conseqüências programadas para o seguimento de regras
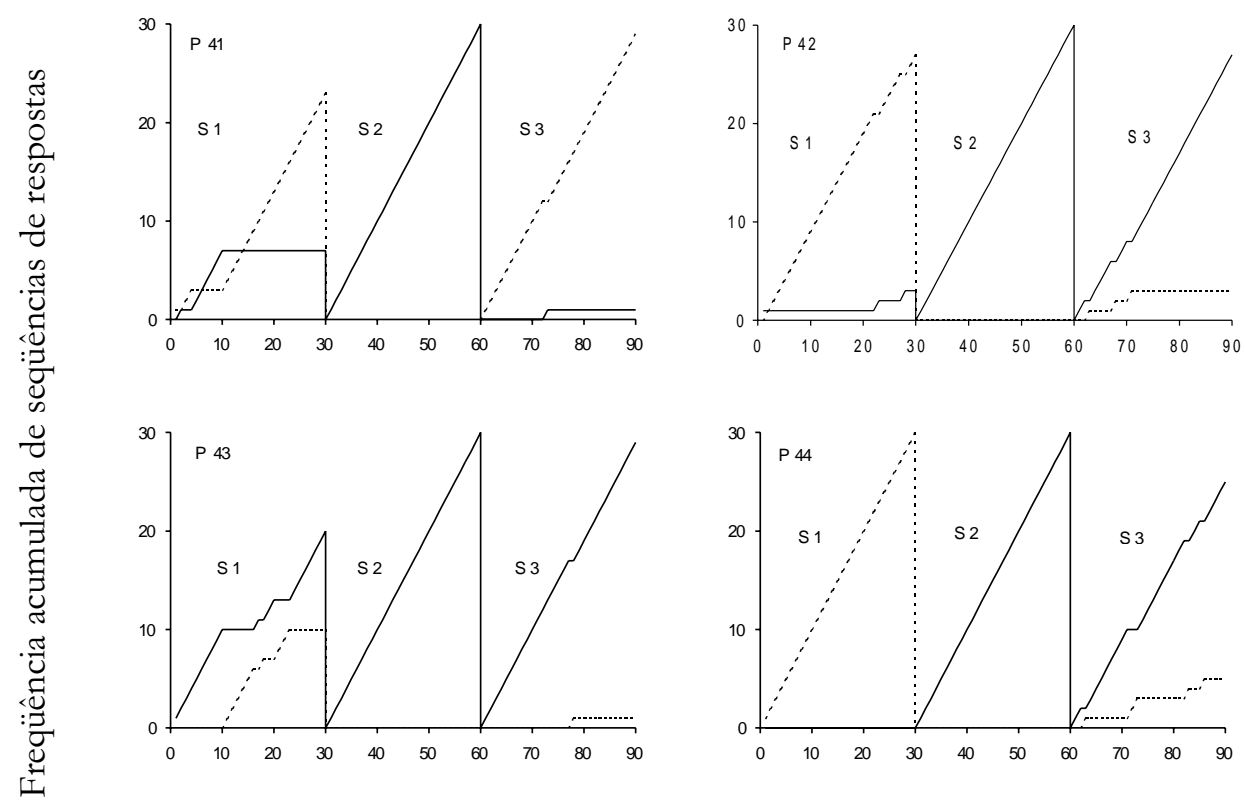

Tentativas

Figura 4. Freqüência acumulada de seqüências de respostas corretas (linha sólida) e incorretas (linha tracejada), para cada participante $(\mathrm{P})$ da Condição IV, durante cada sessão (S) experimental. Quebras na curva acumulada indicam mudanças de sessão.

(Baron \& Galizio, 1983; Cerutti, 1989; Galizio, 1979; LeFrancois e colaboradores, 1988; Paracampo e colaboradores, 1993); o tempo de exposição do seguimento de regra à discrepância instrução / conseqüências programadas (Bernstein, 1988; Michael \& Bernstein, 1991; Hayes e colaboradores, 1986b; Shimoff e colaboradores, 1981) e a história de reforçamento para o seguimento de regra (Galizio, 1979), são alguns dos fatores que podem afetar o seguimento de regras.

Em adição, os resultados do presente estudo, sugerem que a extensão de uma regra, medida pelo número de diferentes respostas descritas na própria regra, também pode interferir na probabilidade de uma regra vir a ser seguida. Ou seja, os resultados da primeira sessão da Condição II (R1-R2-R1), mostrando que a Regra R1 (regra que especificava uma seqüência com três respostas) foi seguida, mais os resultados da primeira sessão da Condição III (R2-R1-R2), mostrando que a Regra R2 (regra que especificava três seqüências com três respostas cada uma) também foi seguida e os resultados da primeira sessão da Condição IV (R3-R1-R3), mostrando que a Regra R3 (regra que especificava três seqüências com seis respostas cada uma) não foi seguida, sugerem que, quando humanos são confrontados pela primeira vez com uma 
regra, eles podem ou não emitir o comportamento especificado pela regra, dependendo, em parte, da extensão da regra, isto é, do número de diferentes respostas descritas na regra.

Observando apenas os resultados da primeira sessão das Condições II (R1-R2-R1), III (R2-R1-R2) e IV (R3R1-R3), poder-se-ia dizer que, quanto maior a extensão de uma regra (isto é, quanto maior o número de diferentes respostas descritas na regra) menor a possibilidade dessa regra ser seguida e que, quanto menor a extensão de uma regra (isto é, quanto menor o número de diferentes respostas descritas na regra) maior a possibilidade dessa regra ser seguida.

Contudo, os resultados da Condição IV (R3-R1-R3), mostrando que a Regra R3 chegou a ser seguida na terceira sessão, depois dos participantes terem sido expostos às contingências de reforço programadas para o seguimento da Regra R3 na primeira sessão e às contingências e reforço programadas para o seguimento da R1 na segunda sessão dessa condição, sugerem que a história de reforçamento diferencial para o seguimento de regras com diferentes extensões também deve ser considerada como uma condição antecedente que pode facilitar o controle do comportamento por uma regra extensa.

Além de contribuir para delimitar as condições sob as quais o seguimento de regras é mais ou menos provável de ocorrer, os resultados do presente estudo também apoiam algumas sugestões acerca de alguns dos efeitos de regras sobre o comportamento humano. Por exemplo, os dados da Condição II (R1-R2-R1), quando comparados com os dados da Condição I (IM), apoiam a sugestão de que o comportamento descrito em uma regra é estabelecido mais rapidamente e apresenta menor variação do que o comportamento estabelecido por contingências (Albuquerque, 1998; Baron \& Galizio, 1983; Joyce \& Chase, 1990); visto que, na Condição I (IM), os participantes passaram a responder seguidamente na seqüência espessura-forma-cor, de acordo com as contingências de reforço programadas nesta condição, só a partir da segunda (caso de P11) ou da terceira sessão (caso de P12, P13 e P14); enquanto que na Condição II (R1-R2-R1), os quatro participantes passaram a emitir seguidamente a seqüência especificada pela Regra R1 (seqüência espessura-forma-cor), imediatamente após a apresentação da Regra R1 na primeira sessão. Portanto, antes de ganhar o primeiro ponto.

Além disso, os resultados do presente estudo também apoiam a sugestão de que regras podem alterar as funções de estímulos (Albuquerque, 1991, 1998; Schlinger e Blakely, 1987). Isto considerando que, na Condição I (IM), provavelmente as dimensões dos estímulos de comparação adquiriram função discriminativa para a seqüência espessura-forma-cor devido à história de reforçamento diferencial da seqüência espessura-formacor na presença dessas dimensões, enquanto que na primeira sessão da Condição II (R1-R2-R1), as dimensões dos estímulos de comparação adquiriram função discriminativa, provavelmente, devido às suas participações prévias na Regra R1.

$\mathrm{Na}$ literatura, a maior parte dos autores concorda que o comportamento de seguir regras é determinado por uma história de reforçamento social para uma correspondência entre a regra e o comportamento por ela descrito (Catania e colaboradores, 1989; Catania, Matthews \& Shimoff, 1990; Hayes, Zettle \& Rosenfarb, 1989) e a maior parte dos estudos, nessa linha de pesquisa, tem procurado investigar a competição entre o controle por regras e o controle por contingências, na tentativa de delimitar quando e sob que condições pode-se dizer que um comportamento é determinado por regras ou por suas conseqüências ou pela interação entre regras e conseqüências. Os resultados do presente estudo sugerem que pesquisas futuras que investigassem que aspectos formais das regras poderiam interferir no próprio comportamento de seguir regras, também poderiam contribuir para delimitar as condições sob as quais o seguimento de regras é mais ou menos provável de ocorrer.

\section{Referências}

Albuquerque, L. C. (1989). Efeitos de regras no controle do comportamento de escolha.Resumos da XIX Reunião Anual de Psicologia da Sociedade de Psicologia de Ribeirão Preto (pp. 422-423). Ribeirão Preto: SBP.

Albuquerque, L. C. (1991). Efeitos de regras no controle do comportamento humano. Comunicações Científicas em Psicologia (p. 162). Universidade Federal do Pará.

Albuquerque, L. C. (1998). Efeitos de Histórias Experimentais sobre o Seguimento Subseqüente de Regras. Tese de doutorado não-publicada, Instituto de Psicologia, Universidade de São Paulo. São Paulo, SP.

Andronis, P. (1991). Rule-governance: Enough to make a term mean. Em L. J. Hayes \& P.N. Chase (Orgs.), Dialogues on verbal behavior (pp.226-235). Hillsdale: Lawrence Erlbaum.

Baron, A. \& Galizio, M. (1983). Instructional control of human operant behavior. The Psychological Record, 33, 495-520.

Baron, A., Kaufman, R. \& Stauber. K. A. (1969). Effects of instructions and reinforcement-feedback on human operant behavior maintained by fixed-interval reinforcement. Journal of the Experimental Analysis of Behavior, 12, 701-712.

Bernstein, D. J. (1988). Laboratory lore and research practices in the experimental analysis of human behavior: Designing session logisticshow long, how often, how many? The Behavior Analyst, 11, 51-58.

Catania, A. C., Matthews, A. \& Shimoff, E. (1990). Properties of rulegoverned behaviour and their implications. Em D. E. Blackman \& H. Lejeune (Orgs.), Behaviour analysis in theory and practice: Contributions and controversies (pp.215-230). Brighton, UK: Lawrence Erlbaum. 
Catania, A. C., Shimoff, E. \& Matthews, A. (1989). An experimental analysis of rule-governed behavior. Em S. C. Hayes (Org.), Rule-governed behavior: Cognition, contingencies, and instructional control (pp.119-150). New York: Plenum.

Cerutti, D. T.(1989). Discrimination theory of rule-governed behavior. Journal of the Experimental Analysis of Behavior, 51, 259-276.

Chase, P. N. \& Danforth, J. S. (1991). The role of rules in concept learning. Em L. J. Hayes \& P. N. Chase (Orgs.), Dialogues on verbal behavior (pp.205225). Hillsdale, NJ: Lawrence Erlbaum.

Galizio, M. (1979). Contingency-shaped and rule-governed behavior: Instructional control of human loss avoidance. Journal of Experimental Analysis of Behavior, 31, 53-70.

Hayes, S. C., Brownstein, A. J., Haas, J. R. \& Greenway, D. (1986). Instructions, multiple schedules, and extinction: Distinguishing rule-governed from schedule-controlled behavior. Journal of the Experimental Analysis of Behavior, 46, 137-147.

Hayes, S. C., Brownstein, A. J., Zettle, R. D., Rosenfarb, I. \& Korn, Z. (1986). Rule governed behavior and sensitivity to changing consequences of responding. Journal of the Experimental Analysis of Behavior, 45, $237-$ 256.

Hayes, S. C., Zettle, R. \& Rosenfarb. I. (1989). Rule-following. Em S. C. Hayes (Org.), Rule governed behavior: Cognition, contingencies, and intructional control (pp.191-220). New York: Plenum.

Joyce, J. H. \& Chase, P. N. (1990). Effects of response variability on the sensivity of rule-governed behavior. Journal of the Experimental Analysis of Behavior, 54, 251-262.

LeFrancois, J. R., Chase, P. N. \& Joyce, J. (1988). The effects of variety of instructions on human fixed-interval performance. Journal of the Experimental Analysis of Behavior, 49, 383-393.

Michael, R. L. \& Bernstein, D. J. (1991). Transient effects of acquisition history on generalization in a matching-to-sample task. Journal of the Experimental Analysis of Behavior, 56, 155-166.

Paracampo, C. C. P. (1991). Alguns efeitos de estímulos antecedentes verbais e reforçamento programado no seguimento de regra. Psicologia: Teoria e Pesquisa, 7, 149-161.
Paracampo, C. C. P., Albuquerque, L. C. \& Fontes, J. C. S. (1993). Análise de algumas das variáveis responsáveis pela manutenção do seguimento de regras. Anais da $45^{\circ}$ Reunião Anual da Sociedade Brasileira para o Progresso da Ciência (p. 984). São Paulo, SP.

Perone, M., Galizio, M. \& Baron, A. (1988). The relevance of animal-based principles in the laboratory study of human operant conditioning. Em G. Davey \& C. Cullen (Orgs.), Human operant conditioning and behavior modification (pp. 59-85). New York: Wiley \& Sons.

Schlinger, H. \& Blakely, E. (1987). Function-altering effects of contingencyspecifying stimuli. The Behavior Analyst, 10, 41-45.

Shimoff, E., Catania, A. C. \& Matthews B. A. (1981). Uninstructed human responding: Sensitivity of low-rate performance to schedule contingencies. Journal of the Experimental Analysis of Behavior, 36, $207-$ 220.

Shimoff, E., Matthews, B. A. \& Catania, A. C. (1986). Human operant performance: Sensitivity and pseudosensitivity to contingencies. Journal of the Experimental Analysis of Behavior, 46, 149-157.

Skinner, B. F. (1978). O comportamento verbal. São Paulo: Cultrix. (Original publicado em 1957)

Skinner, B. F. (1980). Contingências de reforço: Uma análise teórica. Os Pensadores. São Paulo: Abril Cultural. (Original publicado em 1969)

Skinner, B. F. (1982). Sobre o behaviorismo. São Paulo: Cultrix. (Original publicado em 1974)

Torgrud, L. J. \& Holborn, S. W. (1990). The effects of verbal performance descriptions on nonverbal operant responding. Journal of the Experimental Analysis of Behavior, 54, 273-291.

Weiner, H. (1970). Instructional control of human operant responding during extinction following fixed-ratio conditioning. Journal of the Analysis Experimental of Behavior, 13, 391-394.

\section{Sobre os autores:}

Luiz Carlos de Albuquerque é Doutor em Psicologia Experimental pela Universidade de São Paulo; Professor do Departamento de Psicologia Experimental da UFPa e do Programa de PósGraduação em Teoria e Pesquisa do Comportamento da mesma Universidade.

Karina Ferreira é Mestre em Psicologia pela UFPa; Coordenadora do Núcleo de Planejamento da Secretatia Municipal de Saúde de Belém. 


\section{Anexo A}

\section{Instruções Mínimas Dadas aos Participantes para a Coleta de Dados}

"A sua tarefa será ganhar muitos pontos. Para você ganhar pontos, você deve apontar com o dedo para cada um dos três objetos de comparação. Toda vez que apontar na seqüência correta, você vai ganhar um ponto no contador. Tente descobrir qual a melhor maneira de ganhar pontos".

Regra R1 - "Quando eu mostrar estes objetos para você, você deve fazer o seguinte: Primeiro, aponte com o dedo para o objeto de comparação que tem a mesma espessura do objeto modelo. Depois, aponte para o objeto de comparação que tem a mesma forma do objeto modelo. Em seguida, aponte para o objeto de comparação que tem a mesma cor do objeto modelo. Entendeu? Repita para mim o que você deve fazer.

Regra R2 - Quando a lâmpada da esquerda estiver acesa (essa que tem a letra 'E' em cima), você deve fazer o seguinte: Primeiro, aponte com o dedo para o objeto de comparação que tem a mesma cor do objeto modelo. Depois, aponte para o objeto de comparação que tem a mesma forma do objeto modelo. Em seguida, aponte para o objeto de comparação que tem a mesma espessura do objeto modelo.

Agora, quando a lâmpada do centro estiver acesa (essa que tem a letra ' $\mathrm{C}$ ' em cima), você deve fazer o seguinte: Primeiro, aponte com o dedo para o objeto de comparação que tem a mesma forma do objeto modelo. Depois, aponte com o dedo para o objeto de comparação que tem a mesma espessura do objeto modelo. Em seguida, aponte para o objeto de comparação que tem a mesma cor do objeto modelo.

Quando a lâmpada da direita estiver acesa (essa que tem a letra 'D' em cima), você deve fazer o seguinte: Primeiro, aponte com o dedo para o objeto de comparação que tem a mesma espessura do objeto modelo. Depois, aponte para o objeto de comparação que tem a mesma cor do objeto modelo. Em seguida, aponte para o objeto de comparação que tem a mesma forma do objeto modelo. Entendeu? Repita para mim o que você deve fazer.

Regra R3 - Quando a lâmpada da esquerda estiver acesa (essa que tem a letra 'E' em cima), você deve fazer o seguinte: Primeiro, aponte com o dedo para o objeto de comparação que tem a mesma cor do objeto modelo. Depois, aponte para o objeto de comparação que tem a mesma espessura do objeto modelo. Em seguida, aponte para o objeto de comparação que tem a mesma forma do objeto modelo. Depois, aponte para o objeto de comparação que tem a mesma espessura do objeto modelo. Em seguida, aponte para o objeto de comparação que tem a mesma forma do objeto modelo. E por último, aponte para o objeto de comparação que tem a mesma cor do objeto modelo.

Agora, quando a lâmpada do centro estiver acesa (essa que tem a letra ' $\mathrm{C}$ ' em cima), você deve fazer o seguinte: Primeiro, aponte com o dedo para o objeto de comparação que tem a mesma forma do objeto modelo. Depois, aponte para o objeto de comparação que tem a mesma espessura do objeto modelo. Em seguida, aponte para o objeto de comparação que tem a mesma cor do objeto modelo.

Depois, aponte para o objeto de comparação que tem a mesma espessura do objeto modelo. Em seguida, aponte para o objeto de comparação que tem a mesma cor do objeto modelo. E por último, aponte para o objeto de comparação que tem a mesma forma do objeto modelo.

Quando a lâmpada da direita estiver acesa (essa que tem a letra ' $\mathrm{D}$ ' em cima), você deve fazer o seguinte: Primeiro, aponte com o dedo para o objeto de comparação que tem a mesma espessura do objeto modelo. Depois, aponte para o objeto de comparação que tem a mesma cor do objeto modelo. Em seguida, aponte para o objeto de comparação que tem a mesma forma do objeto modelo.

Depois, aponte para o objeto de comparação que tem a mesma forma do objeto modelo. Em seguida, aponte para o objeto de comparação que tem a mesma cor do objeto modelo. E por último, aponte para o objeto de comparação que tem a mesma espessura do objeto modelo. Entendeu? Repita para mim o que você deve fazer. 